\title{
Novos Desafios \\ para a Ciência e \\ Tecnologia em Goiás
}

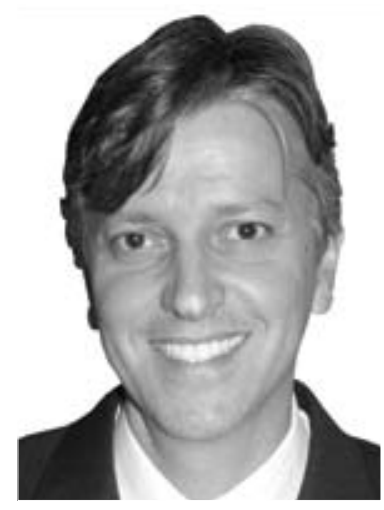

O ano de 2008 será um marco na história da ciência e tecnologia em Goiás. Com a Reforma Administrativa do Estado, o governador Alcides Rodrigues reestruturou completamente a Secretaria de Ciência e Tecnologia (SECTEC), que assume novas funções e estruturas, a exemplo da Educação Profissional do Estado e das Escolas de Governo. Essa redefinição do papel da SECTEC representará em curto prazo a aceleração do processo de desenvolvimento de Goiás, prioritariamente na formação e qualificação de mão-de-obra para suprir a demanda gerada pelo crescimento econômico do Estado.

Nos 14 anos de existência da Secretaria de Ciência e Tecnologia, este entrará para a história como o de maior investimento na área, em fomento à pesquisa. A Fundação de Amparo à Pesquisa (FAPEG) está sendo fortalecida e num trabalho integrado com a SECTEC abre novas perspectivas para o desenvolvimento científico e tecnológico de Goiás. E deveremos fechar o ano com cerca de R \$ 6 milhões aplicados em fomento à pesquisa e a perspectiva é de chegar a R\$ 10 milhões em 2009. Temos muito que comemorar. Este ano Goiás conseguiu o feito de colocar em funcionamento 302 redes de pesquisa, num esforço conjunto da SECTEC e FAPEG.

Consciente de que é preciso aproximar as empresas das universidades para criar ambiente favorável para que as pesquisas geradas transformem-se em produtos e inovação tecnológica, a Secretaria de Ciência e Tecnologia assume, em nossa gestão, o desafio de implantar em Goiás um Centro Tecnológico, com projeto já aprovado pela Secretaria da Fazenda. E estamos buscando subsídios na experiência de Santa Catarina e de Pernambuco. Goiás é um dos poucos Estados que ainda não possui um centro

\author{
É preciso aproximar as \\ empresas das universidades \\ para criar ambiente favorável \\ para que as pesquisas geradas \\ transformem-se em produtos e \\ inovação tecnológica.
}

tecnológico. Já definimos a área da antiga Emater para abrigar o Centro Tecnológico, conjugando laboratórios de excelência, pesquisa, qualificação de mão-de-obra e atração de empresas de base tecnológica para Goiás. Este é o setor que mais cresce no mundo, com uma indústria limpa e que paga salários médios de $\mathrm{R} \$ 2$ mil. O Centro Tecnológico contará ainda com o respaldo do Parque Tecnológico da Universidade Federal de Goiás e toda a estrutura laboratorial da instituição. Será uma área de convivência entre academia, empresa e poder público, em que o Estado funcionará como indutor do crescimento do setor. Estamos redimensionando a área que abrigará o Centro Tecnológico. No local funcionarão várias estruturas de forma integrada, como o Centro de Excelência em Gestão Governamental, que reúne todas as escolas de governo. Os recursos estão assegurados pela Financiadora de Estudos e Projetos (FINEP), uma das agências do Ministério da Ciência e Tecnologia, no valor de R\$ 12 milhões, sendo R \$ 4 milhões para implantação de laboratórios de excelência para servir 
aos cursos de nível técnico e superior (Universidade Estadual de Goiás), principalmente na área de hotelaria e gastronomia. Os outros R $\$ 8$ milhões, destinados à UEG, também para instalação de laboratórios nas regiões de abrangência dos Arranjos Produtivos Locais (APLs). Dois laboratórios já estão definidos, nas áreas de maior demanda de Goiás: Bioequivalência, para atender ao pólo farmoquímico de Anápolis; e Combustíveis Alternativos, biodiesel e etanol.

A educação profissional em Goiás também entra em nova fase, transformando-se num braço forte da Secretaria de Ciência e Tecnologia para atender as demandas de todas as regiões do Estado por formação profissional de nível médio e superior em sintonia com as vocações regionais e necessidade dos investimentos locais. A rede que a SECTEC assume é composta de 19 Centros de Educação Profissional (CEP), implantados em regiões estratégicas do Estado, dos quais cinco foram inaugurados este ano. Os CEPs estão voltados para a formação e qualificação de mão-de-obra nos municípios. Uma de nossas metas é redimensionar, em comum acordo com as prefeituras, a oferta de cursos para atender às demandas locais, contribuindo para a sustentabilidade dos municípios.

Recentemente, fomos a Minas Gerais e Ceará conhecer a experiência desses Estados com os Centros Vocacionais Tecnológicos (CVTs), em busca de subsídios para a reformulação do projeto em Goiás. Temos recursos da ordem de R\$ 13,5 milhões para implantar 17 CVTs, que vão funcionar em prédio de 350 metros quadrados, com laboratórios, mini-auditório e oficina digital. A parceria para colocar os CVTs em funcionamento envolve Governo Federal, que entra com os recursos; as prefeituras, com doação dos terrenos; e Estado, que assume as despesas de manutenção. Também coordenamos 40 oficinas digitais nos municípios, estrutura que veio da Educação.

Outra frente de atuação da Secretaria de Ciência e Tecnologia que se transformou em referência nacional são os Arranjos Produtivos Locais (APLs), uma metodologia em que todos os envolvidos em um aglomerado econômico somam esforços para promover o desenvolvimento sustentável da região, tendo o Estado como indutor, com 51 APLs, sendo 26 consolidados e 25 em formação. Em São Luís de Montes Belos está o APL Lácteo, em estágio mais avançado de desenvolvimento, que colocou em funcionamento a Universidade do Leite, com estrutura de laboratórios e cursos ofertados por várias instituições com foco na cadeia produtiva do leite. Outro APL que começou efetivamente este ano é o da Vitivinicultura do Cerrado, em Santa Helena de Goiás. Fizemos o lançamento firmando parceria com a Embrapa Uva e Vinho Uva e Vinho, de Bento Gonçalves (RS), com a vinda do Chefe Geral Lucas Garrido. A Embrapa quer transformar Goiás numa vitrine nacional. Este APL começa com a realização de um curso técnico de formação para capacitar e qualificar técnicos no manejo da cultura da uva, que será ministrado na Escola Agrícola de Santa Helena, numa parceria SECTEC, UEG, Secretaria da Agricultura e FAEG. E estamos articulando, em conjunto com a Secretaria da Agricultura, para ampliar as ações da Embrapa em Goiás, em segmentos que ajudem a acelerar o desenvolvimento de pesquisas em áreas estratégicas do agronegócio.

A aprovação da Lei de Inovação de Goiás é uma de nossas prioridades, pois o até 2009 o Estado que não contar com essa lei terá problemas para receber recursos federais. A lei permitirá a transferência de recursos, principalmente federais, para o desenvolvimento de pesquisas dentro das empresas. Goiás também tem atuado de forma decisiva pela popularização da ciência. Fechamos o ano com uma conquista, a realização em Goiânia da exposição sobre Darwin, do Museu de História Natural de Nova York, que foi considerada pelo Instituto Sangari (curador da exposição) como a mais bem montada do país. Esta exposição esteve apenas em cinco capitais. E foi trazida numa parceria entre SECTEC, Secretaria de Educação, FAPEG e Instituto Sangari. Para o próximo ano, pretendemos trazer a exposição sobre Einstein. O objetivo é popularizar a ciência e estimular o gosto pela pesquisa de crianças e adolescentes. A exposição de Darwin, por exemplo, recebeu a visita de 30 mil estudantes. Também estamos finalizando projeto para a criação do Museu de Ciência e Tecnologia de Goiás. Visitamos o museu de Nova York e estamos buscando parcerias para o projeto, que tem verba disponível da FINEP. Também de forma exemplar, Goiás investiu recentemente $\mathrm{R} \$ 1,5$ milhão no seu Sistema de Meteorologia, que é referência nacional e atualmente hospeda seis estados do Nordeste.

Comemoramos todas as essas conquistas conscientes dos novos desafios que se impõem. Caminhamos muito e 
de maneira firme. Mas acelerar o passo é nossa obrigação, porque as novas demandas do Estado exigem. Esses desafios nos animam a seguir em frente com a missão de agregar cada vez mais ciência e tecnologia ao processo de desenvolvimento de Goiás. Comemoramos os resultados alcançados em 2008, na certeza de que plantamos uma semente boa para uma colheita farta em 2009.

\section{Joel Sant'ana Braga Filho}

Secretário de Ciência e Tecnologia do Estado de Goiás 